\title{
The Effectiveness of Entonox When Comparing to Pethidine for Labor Pain: A Systematic Review
}

\author{
Thilini Subasinghe
}

\author{
University of Sunderlad, England
}

\begin{abstract}
Several type of analgesia are used to relieve the labour pain. Each method has variations in effectiveness and risk and benefits. This study was conducted to detect the best analgesia to manage labour pain among pethidine and Entonox. The aim of this study was to compare Entonox and pethidine to identify the most effective method to manage the labour pain. Systematic review of six primary quantitative studies, which were done according to the randomized control trial was conducted. Inclusion criteria were term, normal cephalic fetus in active phase of labour mothers who were having pethidine or nitrous oxide (Entonox) as labour analgesia. This study consisted of 596 participants worldwide. Findings reveal that Entonox helps to reduce the duration of labour, severity of labour pain and higher satisfaction than pethidine. In Conclusion, Entonox has more beneficial effects to relieve labour pain in the first stage of labour than pethidine.
\end{abstract}

Keywords: Labour pain, best analgesia, Entonox, pethidine

\section{Introduction}

Labour pain is considered as one of the most severe and intolerable pain in the world. Since 1880, Nitrous oxide $\left(\mathrm{N}_{2} \mathrm{O}\right)$ / Oxygen $\left(\mathrm{O}_{2}\right)$ mixtures was used in obstetric practice as inhalation analgesia for labor (Rosen, 2002). Gradually the gas inhalation practice was developed up to invention of self-administrable machine. In 1934 Minnitt has intended a self-administration machine to inhale nitrous oxide (Agah et al., 2014). The composition of Entonox is 50\% Nitrous Oxide and 50\% Oxygen in a cylindric container (Agah et al., 2014). Many countries use Entonox as a labor analgesia (Biro, Waldenstrom \& Pannifex, 2000). While using Entonox, most suitable technique is important to achieve the maximum effect of inhalation method. Entonox should be inhaled before 30- 50 second of each contraction (Rooks, 2011) and 10 breaths or 50-second inspiration is adequate for analgesia once (Rooks, 2007). Nitrous oxide diffuses through the alveolar and has low solubility in the blood (Faddy and Garlick, 2005). Nitrous oxide affects to GABAA receptors and N-methyl-D-aspartate receptors (Ommanouil, 2007). Entonox releases dopamine and endorphin in the brain (Collins et al., 2012) and that mechanism reduce the labor pain into a tolerable level.

Entonox is tasteless, colorless and odorless gas, easy to use with the advantage of rapid onset short duration and rapid offset (King \& Wong 2014). Entonox can be used even patient has hepatic disease, or renal disease because it is totally filtered by lungs (Brophy \& Bond, 2009). Entonox has minimal toxicity, absence of odor and lack of inflammability as characteristics (Rooks, 2007). The usage of Entonox was increased because it is cost effective and has minimum side effects (King \& Wong 2014). If drowsiness and vomiting appears as side effects while using Entonox, it is disappeared after stop of inhalation (King and Wong 2014). The process reverse after discontinuing of Entonox (Bishop, 2007).

Entonox does not affect badly to the neurological, cardiovascular and respiratory system of mother and the fetus. No side effects were seen from the mothers and fetus which were inhaled Entonox gas (Talebi et al., 2009). If Entonox crosses the placenta, it may not any harm to the baby because none of study, which done regarding Entonox, has not revealed about a harm to the baby. No any relationship identified between neonatal outcome and usage of Entonox (Rooks, 2007). 
Entonox does not depress the respiration like opioids and lack of effect for uterine contraction are considered for increasing of usage of Entonox (Rosen, 2002). Entonox does not affect to the maternal pushing during the labor and length of labor (Collins et al., 2012). Because of them Entonox is used in worldwide such as United Kingdom, Australia, Canada, New Zealand and Finland (Rosen, 2002). In England and both Asian and European countries have been using it for 60 years.

Pethidine is a synthetic opioid and it is synthesized in 1932 (Manouchehrian \& Bakhshaei, 2014). After that it is widely used all over the world as labor analgesia. Pethidine is a widespread in New Zealand (Saravankumar et al., 2007) and practices as a routine method throughout the UK (Tsui et al., 2004). In the UK, all midwives got autonomy to prescribe pethidine for mothers who are in first stage of labor in 1950 (Squire, 2000). Intramuscular pethidine absorbs over six hours and mean time of plasma concentration is 24 minutes. New Zealand Ministry of Health (2012), pointed out that pethidine starts to work in 10- 20 minutes and last in two to four hours after administration.

Complications are occurred both mother and neonate by administrating Pethidine for labor pain (New Zealand Ministry of Health, 2012). Pethidine affect to the central nervous system and it may cause sleepiness, sedation and reduced pain (Mander, 2010). Further pethidine bind to the mu receptors and can cause nausea, vomiting, pruritis, euphoria, respiratory depression, urine retention, mediating sedation as well as analgesia (Anderson, 2011). Sedation, nausea, vomiting, dizziness, hypoxia and itching present as side effects for mothers who are having pethidine opioids. (Jantjes, Strumpher \& Kotze, 2007). Pethidine affect to the fetal circulation (Rooks, 2011). After the intramuscular injection of pethidine, it crosses the placenta by passive diffusion and become high fetal plasma concentration after two three hours (Tuckey, Prout \& Wee, 2008). The acidic environment of the fetal circulation may affect to maintain high concentration of the fetus than mother who was injected from pethidine intramuscular (Sosa et al, 2006). It may affect to the baby in a bad way like reducing Apgar score and respiratory distress (Wang, Shen \& guo et al., 2009). The remain dose of pethidine is metabolized in the baby's liver after the birth (Goodson \& Martis, 2014).

\section{Methods}

Research question is developed from using PICO. Population, Intervention, Comparison and outcome are revealed through PICO. In this study, P- Pregnant mothers in labor, I- Entonox, C- Pethidine, O- Effectiveness of Entonox for labor pain. Science direct, Discover and PubMed were used to search literature in this study and Google scholar is not used as a search engine. Studies from google scholar and examination of reference list of previously selected articles were used as additional records to search literature. PICO terms were applied to those data based. The key words were Entonox, Pethidine, effectiveness analgesia, labor pain. Abstract and title were helped to search relevant literature. Published studies were chosen carefully and full text articles were read by the researcher. Moreover, the literature was evaluated by two health services researchers.

\section{Inclusion Criteria}

Randomized controlled trials are used to compare one treatment with another in a primary study and that design increase the effectiveness of primary study. Studies which were undergone by randomized controlled trials were selected. Those primary studies revealed effectiveness of Entonox and some studies compared both methods in labor pain management. Pregnant mothers who experienced normal vaginal delivery were the participants in those studies and exposed to Nitrous oxide (Entonox).

\section{Exclusion Criteria}

All articles which contains labor analgesia without considering pethidine and Entonox were excluded without considering outcome of the study. Further studies which mentioned other analgesia were removed without any 
hesitation. Duplicated studies were also excluded without any hesitation while using the data filtering process. Qualitative studies and articles which were not written in English were also excluded.

\section{Rating quality of individual studies}

The Cochrane risk of bias tool was used to assess the quality of the selected articles (Higgins et al., 2011). Fundamental domains include sequence generation, allocation concealment, blinding, completeness of outcome data, and selective reporting bias. Two investigators independently assessed the quality of individual studies. According to the rating quality of individual studies, "good", "fair" and "poor" standards were used (Likis et al., 2012).

\section{Evidence synthesis and grading strength of evidence}

Strength of evidence for the effectiveness of Entonox when comparing to pethidine for labor pain was analyzed after the data extraction and quality assessment (Likis et al., 2012). Evidence of the following domains; risk of bias, consistency of findings, directness and precision, were graded. Grades of above domains were combined to develop the grades of key outcome as high, moderate, low. The body of the evidence synthesis was independently assessed by an investigator.

Text that summarizes the research evidence is organized by Key Questions (KQ). Within each KQ, evidence is organized by aspects of the question, such as the compared intervention and outcomes.

\section{Results}

\section{Screening Process}

Articles were selected from 2000 to 2016 and 24700 articles were highlighted in there. Then those articles were reduced to 4212 by searching 2010 to 2016. (PubMed-310, Science Direct-552, Discover-748, from reference list- 2, Google Scholar-2600). (Figure. 1). Then duplicate articles were removed and 2752 records were screened. Irrelevant articles were discarded and the total articles were reduced to 42 . Thereafter 20 systematic reviews were eliminated by reviewing their abstract, titles and texts. Then total number was reduced to 22 . Those 22 articles were read carefully. 11 articles were excluded because they were not relevant to inclusion criteria. Two articles were excluded because they were focused only neonatal outcome. Three articles were excluded because they were mentioned about more than three analgesia in their studies. Two studies were eliminated because they were not related to the research question. Four articles were excluded because their study design is not appropriate. Moreover, five articles were removed due to wrong intervention. Finally, only six studies were remained after the screening process. Six randomized controlled trials were included to the final articles. Table 1 provide an overview of included studies. 


\section{PRISMA FLOW DIAGRAM}

웜

Records identified through data-

base searching

$(n=1610)$

(PubMed-310, Science Direct-

552, Discover-748)

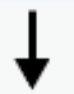

Records after duplicate removed ( $n=2752)$

을

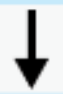

Records screened ( $n=2752)$

Records excluded $(n=2710)$

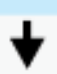

Full text articles assessed

for eligibility $(n=42)$

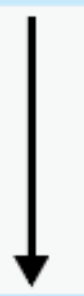

Studies included in qualitative synthesis $(n=6)$

Additional records iden-

tified through other

sources $(n=2602)$

(Google Scholar-2600,

From reference lists-2)

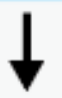

Full text articles excluded

with reasons $(n=36)$

Systematic reviews- 20

Not relevant inclusion

criteria- 11

Wrong intervention- 5

Figure 1. The flow chart illustrates the data filtering process of the systematic review

\section{Effectiveness of Entonox when comparing to pethidine for labor pain}

Six randomized control trials addressed the effectiveness of Entonox when comparing to pethidine for labor pain. Three studies compared Nitrous oxide (Entonox) with pethidine for reducing labor pain during the active phase of labor and findings revealed that inhaled nitrous oxide seems to give better pain relief in than pethidine (Muslih et al., 2010; Teimoori et al., 2011; Mobaraki et al., 2016).

In one study, 400 women in the first stage of labor dived to two groups as Entonox and oxygen and Intravenous (IV) pethidine $0.5 \mathrm{mg} / \mathrm{kg}$ was administered to the both groups when necessary (Attar., 2016). The findings revealed that pethidine requirement, significantly was lower in the Entonox group (p< 0.001) (Attar., 2016). One study assessed the maternal expectation and experiences of labor analgesia with Nitrous oxide (Entonox) and there was a difference between the expectations of women in intervention group and the efficacy of Entonox gas ( $\mathrm{p}=0.001$ ) (Pasha et al., 2012). In a study with 200 pregnant women revealed Entonox is more effective to reduce pain during labor and delivery (Najefian et al., 2013). 
Table 1: Summary of Randomized Controlled Trials

\begin{tabular}{|c|c|c|c|c|c|c|}
\hline $\begin{array}{l}\text { Study, } \\
\text { country }\end{array}$ & $\begin{array}{l}\text { Sample } \\
\text { size }\end{array}$ & $\begin{array}{l}\text { Study } \\
\text { type }\end{array}$ & Quality & $\begin{array}{l}\text { Nitrous } \\
\text { oxide - } \\
\text { administrati } \\
\text { on method }\end{array}$ & Comparator & $\begin{array}{l}\text { Primary outcome for effectiveness of } \\
\text { Entonox for labor pain and women's } \\
\text { satisfaction with their birth experience } \\
\text { and labor pain management }\end{array}$ \\
\hline $\begin{array}{l}\text { Attar et } \\
\text { al., } 2016 \\
\text {; Iran }\end{array}$ & 200 & $\mathrm{RCT}$ & Good & $\begin{array}{l}\text { Entonox } \\
(50 \%) \text {; self } \\
\text { administere } \\
\text { d \& IV } \\
\text { Pethidine } \\
0.5 \mathrm{mg} / \mathrm{kg} \\
\text { when } \\
\text { severe pain }\end{array}$ & $\begin{array}{l}\text { Oxygen } 4-6 \\
\text { lit/min \& IV } \\
\text { Pethidine } 0.5 \\
\text { mg/kg when } \\
\text { severe pain }\end{array}$ & $\begin{array}{l}\text { Entonox significantly reduced pain } \\
\text { during delivery without significant } \\
\text { increase in maternal and neonatal } \\
\text { complication. } \\
\text { Pethidine requirement was lower in the } \\
\text { Entonox group ( }<<0.001 \text { ). } \\
\text { Complications such as nausea, } \\
\text { vomiting, dizziness and drowsiness- } \\
\text { seen } 25 \% \text { in Entonox group and } 23 \% \\
\text { in control group. }\end{array}$ \\
\hline $\begin{array}{l}\text { Mobarak } \\
\text { i et al., } \\
2016 \text {; } \\
\text { Iran }\end{array}$ & 100 & RCT & Fair & $\begin{array}{l}\text { Entonox ; } \\
\text { self } \\
\text { administere } \\
\text { d }\end{array}$ & $\begin{array}{l}\text { IM Pethidine } \\
0.5 \mathrm{mg} / \mathrm{kg}\end{array}$ & $\begin{array}{l}\text { Entonox convenient to administer than } \\
\text { intramuscular Pethidine. } \\
\text { Entonox- Safe for mother and baby. } \\
\text { Greater maternal satisfaction is noticed } \\
\text { in entonox group than pethidine group. } \\
\text { Inhaled entonox give better pain relief } \\
\text { in short term compared to single dose } \\
\text { of pethidine (after } 30 \text { minues } p=0.001 \text { ). } \\
\text { But no significant difference in the } \\
\text { severity of the pain between Entonox } \\
\text { and Pethidine groups } 60 \text { minutes after } \\
\text { intervention ( }>0.05 \text { ). } \\
\text { No significant difference was observed } \\
\text { between infant complications and } \\
\text { Apgar scores in both Pethidine and } \\
\text { Entonox groups ( }>0.05 \text { ). }\end{array}$ \\
\hline $\begin{array}{l}\text { Najefian } \\
\text { et al., } \\
2013\end{array}$ & 200 & RCT & Good & $\begin{array}{l}\text { Entonox } \\
(50 \%) \text {; self } \\
\text { administere } \\
\text { d }\end{array}$ & Oxygen & $\begin{array}{l}\text { Entonox- } \\
\text { labor duration is shorter in the } \\
\text { Entonox group than control group } \\
\text { ( } \mathrm{p}=0.03 \text { ). } \\
\text { Severity of labor pain low than control } \\
\text { group }(\mathrm{p}<0.002) \text {. } \\
\text { Side effects of Entonox; lethargy } \\
40.1 \% \text {, dry mouth } 31 \% \\
\text { Not seen severe side effects on mother } \\
\text { and baby. } \\
\text { Entonox is safe and effective for labor } \\
\text { pain. }\end{array}$ \\
\hline $\begin{array}{l}\text { Pasha } \\
\text { et al., }\end{array}$ & 98 & RCT & Fair & $\begin{array}{l}\text { Entonox } \\
(50 \%) ; \text { self }\end{array}$ & Oxygen $50 \%$ & $\begin{array}{l}\text { Entonox- } \\
\text { severity of labour pain is lower in }\end{array}$ \\
\hline
\end{tabular}




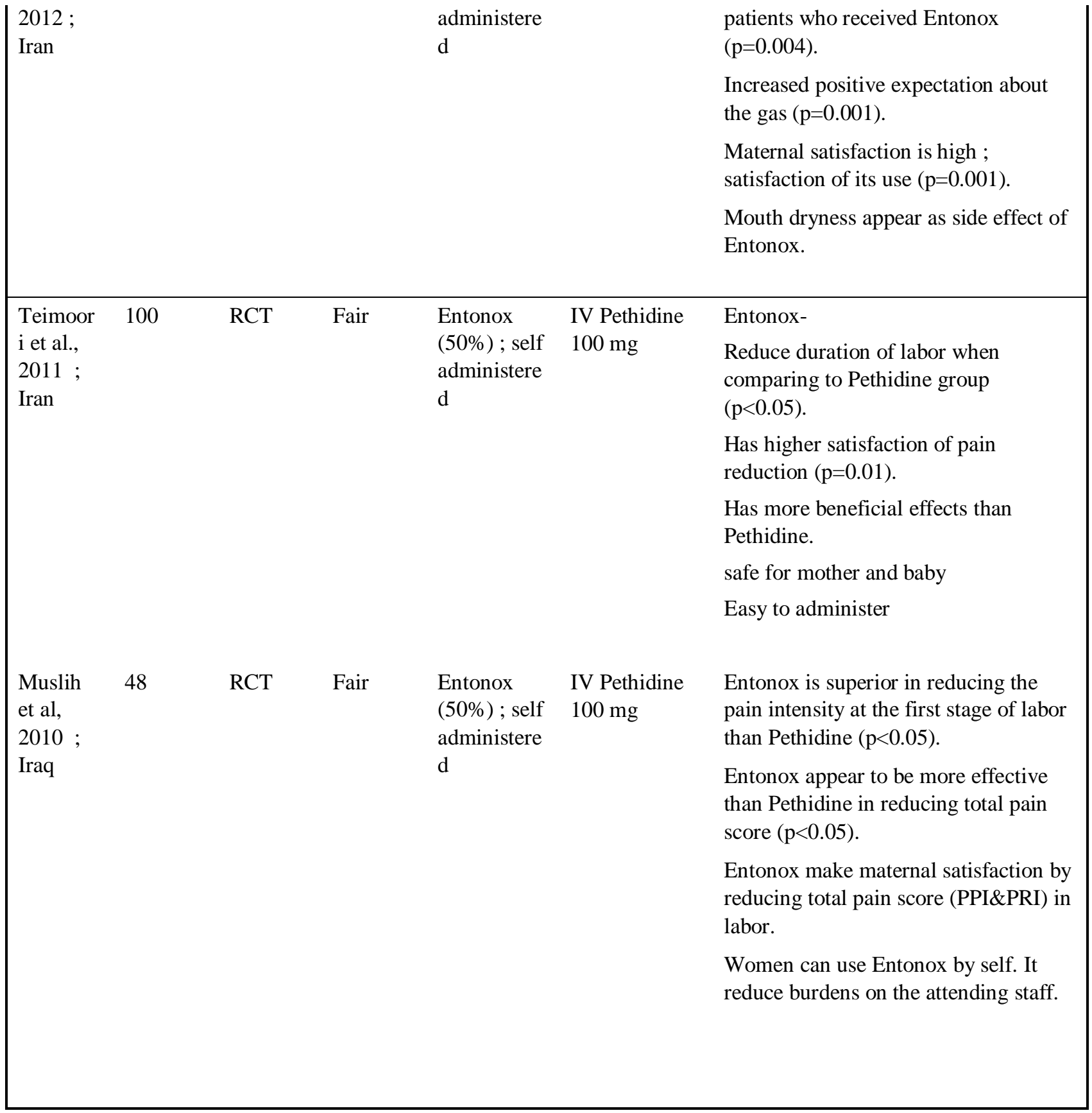

Table 1. Summary of Randomized Controlled Trials.

RCT $=$ randomized controlled trial. The oldest study was conducted in 2010 and the latest one was conducted in the year 2016.

\section{Safety of both mother and neonate}

Three studies addressed the safety of both mother and neonate (Muslih et al., 2010, Teimoori et al., 2011, Mobaraki et al., 2016). Participants who had taken Entonox had low heart rate and respiratory rate after the 1st stage and 2nd stage of labor (Teimoori et al., 2011). No significant different was observed among the groups regarding infant complication therefore, neonatal outcome is same both Entonox and Pethidine group (Teimoori et al., 2011). A study involving 48 participants revealed that Entonox shows minimal maternal toxicity, ability of self-administration without disturbing to the staff and non-affect for neonate (respiratory distress) (Muslih et al., 2010). The Apgar score was not showed any difference between Entonox and Pethidine group (Mobaraki et al., 2016). 


\section{Severity of maternal side effects}

Severity of maternal side effects was addressed by five RCTs (Muslih et al., 2010, Pasha et al., 2012, Najefian et al., 2013, Mobaraki et al., 2016, Attar et al., 2016). Entonox has minimal maternal toxicity (Muslih et al., 2010). A study conducted to assess the effect of Entonox during the labor highlighted $40.1 \%$ had lethargy, $20 \%$ vomiting $31 \%$ dry mouth, $11 \%$ vomiting and $1.2 \%$ felt discomfort after administration of Entonox (Najefian et al., 2013). No significant difference was seen in the maternal complication ( $p>0.05$ ) (Mobaraki et al., 2016). However, mouth dryness was higher in the nitrous oxide users $(\mathrm{p}=0.044)$ (Mobaraki et al., 2016). Complications such as vomiting, dizziness and drowsiness seen in Entonox group (25\%) and control group $(23 \%)$.

\section{Severity of labor pain}

All six studies addressed the severity of labour pain (Muslih et al., 2010, Teimoori et al., 2011, Pasha et al., 2012, Najefian et al., 2013, Mobaraki et al., 2016, Attar., 2016). Two studies compared the effectiveness of analgesia between Entonox and Pethidine and finally confirmed that Entonox reduce the severity of labor pain than Pethidine during the labor ( $\mathrm{p}<0.05$ ) (Muslih et al., 2010, Teimoori et al., 2011). The severity of pain is law in the group who had taken Entonox than Pethidine after 30 minutes but, it did not show any difference after 60 minutes because the mean time of maximum plasma concentration of pethidine is 24 minutes (Mobaraki et al., 2016). Multiparous mothers have given their experience as Entonox reduced labor pain this time than previous deliveries (p<0.05) (Pasha et al., 2012). A study conducted to find the effectiveness of Nitrous oxide (Entonox) on labor pain revealed that the labor pain is significantly low the group which having Entonox than control group (p<0.05) (Najefian et al., 2013, Attar et al., 2016).

\section{Reduction of labor duration}

Four studies addressed the reduction of labor duration (Teimoori et al., 2011, Najefian et al., 2013, Mobaraki et al., 2016, Attar. 2016). Entonox may help to short the duration of active phase and does not affect to the second stage $(\mathrm{p}=0.03)$ and administration of Entonox increase the vaginal birth because it reduce the labor pain (Najefian et al., 2013).one study highlighted Entonox reduce the labor pain in the first stage and second stage ( $\mathrm{p}<0.05$ ) (Attar et al., 2016). Duration of first and second stage was shorter in Entonox group than Pethidine group ( $\mathrm{P}<0.05$ ) (Teimoori et al., 2011). Any difference of duration of labor did not identified among intervention and control group (Mobaraki et al., 2016).

\section{Maternal satisfaction}

Maternal satisfaction was addressed by four RCT (Muslih et al., 2010, Teimoori et al., 2011; Pasha et al., 2012, Attar et al., 2016). Entonox make maternal satisfaction by reducing total pain score in labor (Muslih et al., 2010). Patient's satisfaction was evaluated by verbally and higher satisfaction of pain reduction was identified in Entonox group (Teimoori et al., 2011). 98\% participants satisfied with having Entonox as an analgesia for labor pain (Pasha et al., 2012). 49\% participant present their experience that having Entonox is excellent to relieve the labor pain $(\mathrm{P}<0.05)$ and increased tendency of using Entonox for labor in the future pregnancies also. (Pasha et al., 2012).

\section{Discussion}

Six primary quantitative researches were reviewed to evaluate the effectiveness of Entonox when comparing to Pethidine as analgesia to relieve the labor pain. Selected studies present their findings as this way. Three of studies which compared effectiveness of Entonox and Pethidine as analgesia for labor pain done by Muslih et al., (2010), Teimoori et al., (2011) and Mobaraki et al., (2016) revealed that Entonox give better pain relief for 
labor pain than Pethidine and Entonox is safe for both mother and neonate. Two studies Pasha et al., (2012) and Najefian et al., (2013) presented their findings as usage of Entonox reduce labor pain effectively. Entonox is cheap, safe and easily available and none of severe side effects for both mother and baby (Najefian et al., 2013). Further, maternal satisfaction is high on mothers who had taken Entonox during the labor (Pasha et al., 2012). Entonox reduce labor pain without maternal and neonatal complications (Attar, 2016).

In this study, Muslih et al., (2010) reported that Entonox is safe for baby because they have not noticed any respiratory depressant of newborn in Entonox group. Further, they stated minimal maternity toxicity was seen in Entonox group. Therefor Entonox is safe for both mother and baby. Teimoori et al., (2011) also accepted that Entonox is safe for mother and baby compared to Pethidine. Mobaraki et al., (2016) has not exclude any difference of neonatal out come between Entonox group and Pethidine group. Further he identified none of difference noticed regarding Apgar score and neonatal complication in both Entonox and Pethidine group. Although Najefian et al., (2013) noted that severe side effects not seen on both mother and neonate compared to Entonox to control group (Oxygen), Pasha et al., (2012) does not mentioned anything regarding neonatal outcome. In contrast Tsui et al., (2004) mentioned that Pethidine shows no any difference in neonatal outcome compared to control group. Therefor this study noted that Pethidine also safe for baby. Nevertheless, Jones et al., (2012) and Wang et al (2009) noted that fetal distress may occur in short time after Pethidine administration. Those studies supported to say that Entonox is safe for both mother and baby.

Nausea, vomiting and maternal sedation are associated with Pethidine (Tsui et al., 2004). Entonox has minimal maternal toxicity (Muslih et al., 2010). Entonox presents loss of consciousness (Teimoori et al., 2011). Entonox presents dry mouth (pasha et al., 2012, Mobaraki et al., 2016). Najefian et al., (2013) report that $40.1 \%$ lethargy, dry mouth $31 \%$ and vomiting, vertigo also seen in Entonox. Entonox reported 36\% nausea and vomiting as side effects (Rooks, 2007) and 24\% reported dry mouth, drowsiness, dreams and dizziness during the administration of Entonox (Bishop, 2007). However, effects of Entonox is reversible by discontinuation of administration and can control the side effects (Bishop, 2007). Therefore, the above findings reflect that Entonox has minimum side effects than pethidine.

Muslih et al., (2010), Teimoori et al., (2011) and Mobaraki et al., (2016) noted that severity of pain is law in Entonox group than in Pethidine use. Pasha et al., (2012) Najefian et al., (2013) supported this statement by presenting evidence that Entonox reduce the intensity of pain in labor than control group. Entonox significantly reduced labor pain and pethidine requirement was lower in the Entonox group (Attar et al., 2016). Entonox has an anxiolytic effect and reduce the perception of labor pain (Rooks, 2011). According to the above studies severity of labor pain is law in Entonox. However, further researches are needed to support the extracted findings.

According to the findings of this study, Entonox reduce the duration of labor (Teimoori et al., 2011, Najefian et al 2013, Attar et al., 2016). Further, Tazarjani et al. (2010) supported that statement. However, Mobaraki et al, (2016) highlighted that Entonox had no any influence to reduce the duration of labor. Therefore, it is crucial to address further researches to address the relationship between duration of labour and usage of Entonox.

Teimoori et al., (2011) reported that women who were having Entonox had higher satisfaction than pethidine regarding relief of labor pain. Pasha et al., (2012) and Attar et al., (2016) reported that mothers who had Entonox had higher satisfaction. Further, wee et al., (2011) also supported the above statement. Muslih et al., (2010) Najefian et al., (2013) and Mobaraki et al., (2016) did not mention any thing regarding maternal satisfaction of having analgesia. Nevertheless, Tsui et al. (2004) reported that satisfaction score was high in Pethidine group after 30 minutes of administration. Hence, the above evidence reflects the necessary of further research to address the satisfaction of Entonox.

In summary, the literature addressing Pethidine and Entonox for the management of labor pain includes few studies of good or fair quality. As a result, 


\section{Limitation}

Petticrew and Roberts (2008) mentioned that systematic review should be done by group of researchers. Khan et al., (2011) also supported to that statement. Although a group of researchers develop a standard quality of research Bettany-Saltikov (2010) mentioned that a single researcher also suitable to develop a standard study by following recommended guidelines. The oldest study which was used in this study was conducted in 2010.

\section{Recommendation}

Follow up is a most crucial thing to develop the nursing and obstetric practice. Therefor future researches are recommended to evaluate the effectiveness of medication which are currently used. Furthermore, maternal satisfaction and neonatal outcome of the labor analgesia should be evaluated through the research.

\section{Conclusion}

In conclusion this systematic review met the objectives of the research question by obtaining evidence from selected articles. Entonox has less side effect except mouth dryness, reduce duration of labor and severity of labor pain and higher maternal satisfaction than Pethidine. Further Entonox is considered as safe for both mother and baby than Pethidine. Therefor this study reveal that Entonox is an effective analgesia to reduce the labor pain than Pethidine.

\section{Acknowledgment}

The author would like to offer special thanks to Mr. Prakash Ranasinghe for the continuous support. Further, the author owes the gratitude to Mr. Sunil de Silva, Ms. Pamudika Madawi and Ms. Deepika Priyadarshani for assisting the quality of individual studies.

\section{References}

Agah, J., Baghani, R., Tali, S. S. \& Tabarraei, Y. (2014). Effects of continuous use of Entonox comparison with intermittent method on Obstertric Outcomes: A randomized Clinical Trial. Journal of Pharmaceutical Health, 15(2):641-646.

Anderson, D. (2011). A review of systemic opioids commonly used for labor pain relief. Journal of Midwifery and Women's Health, 56, 222-239.

Attar, A. S., Feizabadi, A. S., Jarahi, L., Feizabadi,S. L., \& Shebani, S. (2016). Effect of Entonox on reducing the need for Pethidine and the Relevent Fetal and Maternal Complications for painless labour. Electron Physician, 81(12): 3325-3332.

Bettany-Saltikov, J. (2010). Learning how to undertake a systematic review: part 2. Nursing Standard, 24(51), 47-56.

Biró, M. A., Waldenström, U. \& Pannifex, J. H. (2000). Team midwifery care in a tertiary level obstetric service: a randomized controlled trial. Birth, 27: 168-173.

Bishop, J. T. (2007). Administration of Nitrous Oxide in Labor: Expanding the Options for Women. J Midwifery \& Women's Health, 52: 308-309.

Brophy, S. \& Bond, C. (2009). Pain Management Nitrous-Oxide Administration via Nitrous Mixer. Centerburg District Health Board.

Collins, M. R., Starr, S. A., Bishop, J. T. \& Baysinger, C. L. (2012). Nitrous oxide for labor analgesia: expanding analgesic options for women in the United States. Reviews in Obstetrics \& Gynecology, 5(3), 126131. 
Faddy, S. C. \& Garlick, S. R. (2005). A systematic review of the safety of analgesia with 50\% nitrous oxide: can lay responders use analgesic gases in the prehospital setting?. Emerg Med J, 22(12):901-8. doi:10.1136/emj.2004.020891. [PubMed: 16299211].

Goodson, C. \& Martis, R. (2014). Pethidine: to prescribe or not to prescribe? A discussion surrounding pethidine's place in midwifery practice and New Zealand prescribing legislation. New Zealand College of Midwives Journal, 49, 24.

Higgins, J. T., Altman, D. G. \& Sterne, J. C. (2011). Chapter 8: Assessing risk of bias in included studies. In: Higgins JPT, Green S, eds. Cochrane Handbook for Systematic Reviews of Interventions Version 510, The Cochrane Collaboration.

Khan, K., Kunz, R., Kleijnen, J., \& Antes, G. (2011). Systematic reviews to support evidence- based medicine. Crc Press.

King, T. L. \& Wong, C. A. (2014). Nitrous Oxide for labor pain:Is it a laughing matter? Anesthesia and Analgesia, 118 (1): 12-14.

Jantjes, L., Strumpher, J. \& Kotze, W. (2007). The experience of childbirth [sic] infirst-time motherswho received narcotic analgesics during the first stage of labour. Curationis, 30(2), 82-90. The CINAHL database: http://www.ncbi.nlm.nih.gov/pubmed/17703826.

Likis, F. E., Andrews, J. A., Collins, M. R., Lewis, R. M., Seroogy, J. J., Starr, S. A., Walden, R. R.\& McPheeters, M. L. (2012). Nitrous Oxide for the Management of Labor Pain. Comparative Effectiveness. Agency for Healthcare Research and Quality, 67.

Mander, R. (2010). Pain in childbearing and its control: key issues for midwives and women. John Wiley \& Sons.

Manouchehrian, N. \& Bakhshaei, M. H. (2014). Nitrous oxide effect on relieving anxiety and pain inparturients under spinal anesthesia for caesarean section. Anesthesiology and pain medicine, 4(2).

Mobaraki, N., Yousefian, M., Seifi, S. \& Sakaku, M. (2016). A Randomized Control Trial Comparing Use of Entonox with Pethidine for Pain Relief in Primigravid Women Durin the Active Phase of Labor. Anesth Pain Med, (In Press): e 37420.

Morgan, B., Bulpitt, C.J., Clifton, P. \& Lewis, P. J. (1982). Effectiveness of pain relief in labour: survey of 1000 mothers. Br Med J, 285:689-90

Muslih, H. A., Ismael, A. H. \& Raoof, E. (2010). Analgesia in labor: Evaluating clinical trial comparing between Entonox versusparenteral pethidine during the first stage of labor. Mustansiriya Medical Journal, 10 (1).

Najefian, M., Cheraghi, M., Pourmehdi, Z. \& Nejad, A. D. (2013). The effect of nitrous oxide (ENTONOX) on labour pain relief during delivery stages. International Journal of Pharmacy \& Therapeutics, 4, 242-246.

NEW ZEALAND MINISTRY OF HEALTH, Pethidine Hydrochloride Injection. Administering thenmedicines 2012. Available from: http:// www.medsafe.govt.nz/profs/datasheet/d/dblPethidineinj.pdf.

Ommanouil, D. E. \& Quock, R. M. (2007). Advances In understanding the action of nitrous oxide.nAnesh Prog, 54(1), 9-18.

Pasha, H., Basirat, Z., Hajahmadi, M., Bakhtiari, A., Faramarzi, M. \& Salmalian, H. (2012). Maternal expectations and experiences of labor analgesia with nitrous oxide. Iran Red Crescent Med J. 14(12): 792-7. doi: 10.5812/ircmj.3470. [PubMed: 23483128].

Rooks, J. P. (2011). Safety and risks of nitrous oxide labor analgesia: a review. J Midwifery Womens Health, 56: $557-65$.

Rosen, M. A. (2002). Nitrous oxide for relief of labor pain: a systematic review. Am J Obstet Gynecol 186: S110- 26.

Saravankumar, K., Garstang, J. \& Hasan, K. (2007). Intravenous patient-controlled analgesia for labour: a survey of UK practice. International Journal of Obstertric Anesthesia, 16, 221-25. 
Sosa, C., Buekens, P., Hughes, J., Balague, E., Sotero, G., Panizza, R., Piriz, H. \& Alonso, J. (2006) Effect of pethidine administered during the first stage of laboron the acid-base status at birth. European Journal of Obstetrics \& Gynecology and Reproductive Biology, 129, 135-139. doi: 10.1016/j.ejogrb.2005.11.033

Squire, C. (2000). Pain relief: past and present. In: Yerby, M. (Ed.). Pain in childbearing: key issues in management. (London, England: Harcourt Publishers Ltd) pp. 1-16.

Talebi, H., Nourozi, A., Jamilian, M., Baharfar, N. \& Eghtesadi- Araghi, P. (2009). Entonox for labor pain: a randomized placebo controlled trial. Pak J Biol Sci, 12(17):217-21.

Teimoori, B., Sakhavar, N., Mirteimoori, M., Narouie, B. \& Ghasemi-rad, M. (2011). Nitrous oxide versus pethidine with promethasine for reducing labor pain. Afr J Pharm Pharmacol, 5(17): 2013-17.

Tsui, M. H., Kee, N., Warwick, D., F. \& Lau, T. K. (2004). A Double blinded Randomised placebo-controlled study of Intramuscular Pethidine for Pain Relief in the first stage of Labour. BJOG: an international journal of obstetrics \& gynaecology, 111(7), 648-655.

Tuckey, J. P., Prout, R. E. \& Wee, M. Y. (2008). Prescribing intramuscular opioids for labour analgesia in consultant-led maternity units: a survey of UK practice. International journal of obstetric anesthesia, 17(1), 3-8.

Wang, F., Shen, X., Guo, X., Peng, Y. \& Gu, X. (2009). Labor Analgesia Examining Group. Epiduralanalgesia in the latent phase of labor and the risk of caesarean delivery: a five-year randomized controlled trial. Anesthesiology. 111: 871-880.

Wee, M. Y., Tuckey, J. P., Thomas, P. \& Burnard, S. (2011). A two-centre randomised double-blind controlled trial comparing intramuscular diamorphine and intramuscular pethidine for labour.nAnalgesia, 11:51.

Yerby, M. (2000). Pharmacological methods of pain relief. In: Yerby, M. (Ed.). Pain in childbearing: key issues in management. (London, England: Harcourt Publishers Ltd), pp. 111-130. 